\title{
Comparison of the Obesity Phenotypes Related to Monosodium Glutamate Effect on Arcuate Nucleus and/or the High Fat Diet Feeding in C57BL/6 and NMRI Mice
}

\author{
R. MATYŠKOVÁ ${ }^{1}$, L. MALETÍNSKÁ ${ }^{1}$, J. MAIXNEROVÁ ${ }^{1}$, Z. PIRNÍK $^{2}$, A. KISS ${ }^{2}$, \\ B. ŽELEZNÁ ${ }^{1}$
}

${ }^{1}$ Institute of Organic Chemistry and Biochemistry, Academy of Sciences of the Czech Republic, Prague, Czech Republic and ${ }^{2}$ Institute of Experimental Endocrinology, Slovak Academy of Sciences, Bratislava, Slovak Republic

Received April 26, 2007

Accepted August 14, 2007

On-line October 11, 2007

\section{Summary}

In this study, susceptibility of inbred C57BL/6 and outbred NMRI mice to monosodium glutamate (MSG) obesity or diet-induced obesity (DIO) was compared in terms of food intake, body weight, adiposity as well as leptin, insulin and glucose levels. MSG obesity is an early-onset obesity resulting from MSGinduced lesions in arcuate nucleus to neonatal mice. Both male and female C57BL/6 and NMRI mice with MSG obesity did not differ in body weight from their lean controls, but had dramatically increased fat to body weight ratio. All MSG obese mice developed severe hyperleptinemia, more remarkable in females, but only NMRI male mice showed massive hyperinsulinemia and an extremely high HOMA index that pointed to development of insulin resistance. Diet-induced obesity is a late-onset obesity; it developed during 16-week-long feeding with high-fat diet containing $60 \%$ calories as fat. Inbred C57BL/6 mice, which are frequently used in DIO studies, both male and female, had significantly increased fat to body weight ratio and leptin and glucose levels compared with their appropriate lean controls, but only female C57BL/6 mice had also significantly elevated body weight and insulin level. NMRI mice were less prone to DIO than C57BL/6 ones and did not show significant changes in metabolic parameters after feeding with high-fat diet.

\section{Key words}

C57BL/6 • NMRI • Mouse - Monosodium glutamate obesity • Diet-induced obesity

\section{Corresponding author}

Blanka Železná, Institute of Organic Chemistry and Biochemistry, Academy of Sciences of the Czech Republic, Flemingovo nám. 2, 16610 Prague, Czech Republic. E-mail: zelezna@uochb.cas.cz

\section{Introduction}

Obesity is associated with conditions such as insulin resistance, dyslipidemia and steatosis hepatitis. Appropriate animal models are crucial for studies on the pathogenesis and therapy of this complex metabolic disorder. Several mouse models of obesity have been established, above them models examining monogenic (such as $o b / o b$ or $d b / d b$ mice), chemically induced (such as monosodium glutamate-induced (MSG) obesity) or diet-induced obesity (DIO) are widely used (for review see Butler and Cone 2001, Buettner et al. 2007).

In this study, outbred (NMRI) and inbred (C57BL/6) mice of both sexes with either MSG obesity or DIO were compared in terms of anatomic and metabolic parameters.

Monosodium glutamate (MSG) obesity with an early onset can be induced to newborn mice with subcutaneous administration of MSG (Olney 1969), which causes lesions in hypothalamic arcuate nucleus (ARC) and impaires leptin and insulin signaling in this region (Broberger et al. 1998, Dawson et al. 1997; Maletínská et al. 2006) resulting in hyperleptinemia and hyperinsulinemia. Although the MSG animals are rather hypophagic (Morris et al. 1998), they have a dramatic increase in body fat, which could be explained rather by a lower metabolic rate than by an elevated food intake (Djazayery et al. 1979). A marked shrinkage of the ARC in the MSG-treated mice impairs production of growth hormone releasing hormone (GHRH) which results in 
shorter body length, atrophied pituitaries, gonads, and optical nerves (Tamura et al. 2002).

Diet-induced obesity (DIO) has a late onset and is developed after feeding mice with high-fat diet (HF diet). It is similar to common human obesity resulting from over-consumption of food and sedentary style of life. Depending on animal strain, gender, as well as composition and duration of feeding with high-fat diet, DIO mice developed increased adiposity that resulted in hyperleptinemia and peripheral leptin insensitivity already at 8 weeks on HF diet (Buettner et al. 2007, van Heek et al. 1997). Later on, failure in down-regulation of food intake by leptin gradually caused central leptin insensitivity (Lin et al. 2000, Zhang and Scarpace 2006). Inbred strains of mice prone to DIO such as $\mathrm{C} 57 \mathrm{BL} / 6$, $\mathrm{AKR} / \mathrm{J}$ or DBA/2J were selected previously (West et al. 1992). C57BL/6J mice were found useful for development of metabolic syndrome (Collins et al. 2004) and altered insulin secretion (Andrikopoulos et al. 2005). However, little is known about DIO development and consequences in female mice. Outbred Wistar and Sprague-Dawley rats were used mostly as standard rodents for studying DIO and insulin resistance (Buettner et al. 2007). On the contrary, DIO in outbred mice is rarely studied.

In this study, we compared predisposition of outbred NMRI and inbred C57BL/6 mice of both sexes to MSG and DIO obesity in terms of possible leptin and/or insulin resistance which could be used for future pharmacological studies concerning food intake regulation.

\section{Methods}

\section{Experimental animals}

NMRI mice (Bio Test, Konárovice, Czech Republic) and C57BL/6 mice (Institute of Molecular Genetics, Prague, Czech Republic) were housed at a temperature of $23{ }^{\circ} \mathrm{C}$ and a daily cycle of $12 \mathrm{~h}$ light and dark (light from 6:00). They were given ad libitum water and standard chow diet that contained 25, 9 and $66 \%$ calories as protein, fat and carbohydrate, its energy content was $3.4 \mathrm{kcal} / \mathrm{g}$ (ST-1, Velaz, Koleč, Czech Republic). All experiments followed the ethical guidelines for animal experiments and the law of the Czech Republic No. 246/1992.

For MSG obesity, newborn mice were administered with MSG (4 mg/g body weight, s.c.) from postnatal day 2 to 8 . "Osmolality" controls were treated with saline of osmolality corresponding to the MSG solution (Ježová et al. 1998).

For DIO development, mice were fed with HF diet $(13,60$ and $27 \%$ calories as protein, fat and carbohydrate, respectively (Kopecký et al. 1996)) from 7 weeks of age. The HF diet was composed of $40 \%$ of the chow diet, $34 \%$ powdered cow milk for human neonates, $25 \%$ sunflower oil and $1 \%$ corn starch. Energy content of HF diet was $5.3 \mathrm{kcal} / \mathrm{g}$.

Food consumption and body weight were monitored every week. Daily food intake (24-h food intake) was determined regularly every week from 6 to 15-16 weeks of age in MSG mice and from 8 to 22 weeks of age in mice with DIO (when mice were on HF). In smaller groups $(n=3)$ of $4-, 8$ - and 12-week-old DIO mice on HF diet, and of their respective controls, fat and body weight were determined.

MSG treated mice at 16 weeks of age $(n=20-25$ for each sex), their age-related naive and "osmolality" controls, DIO mice after 16 weeks on HF diet $(n=20-25$ for each sex), and their age-related controls on standard diet were divided into two subgroups of 10-15 mice. One subgroup was fasted overnight and mice sacrificed next morning between 8:00 and 9:00 a.m. In their blood sera, glucose and insulin levels were determined and HOMA index, i.e. fasting plasma glucose $[\mathrm{mmol} / \mathrm{l}] \mathrm{x}$ fasting plasma insulin [pmol/1] / 22.5, was calculated (Lansang et al. 2001). Mice from the other group with free access to food were also sacrificed between 8:00 and 9:00 a.m. In their blood sera, leptin, glucose and insulin levels were determined. White adipose tissue (subcutaneous, abdominal, and gonadal), and liver of all mice were dissected and weighed.

\section{Brain histology}

Three male and three female MSG-treated mice of 16 weeks of age and their age-related controls were used for the experiment. They were deeply anesthetized and rapidly perfused transcardially with fixative; coronal sections from their hypothalami were prepared and stained as described earlier (Maletínská et al. 2006).

\section{Blood serum components}

Leptin and insulin concentrations in sera were quantified by ELISA assay (BioVendor, Brno, Czech Republic) and by RIA assay (Linco Research, St. Charles, MI, USA), respectively. Serum glucose levels were measured by a glucometer (Glucocard, Arkray, Kyoto, Japan). 

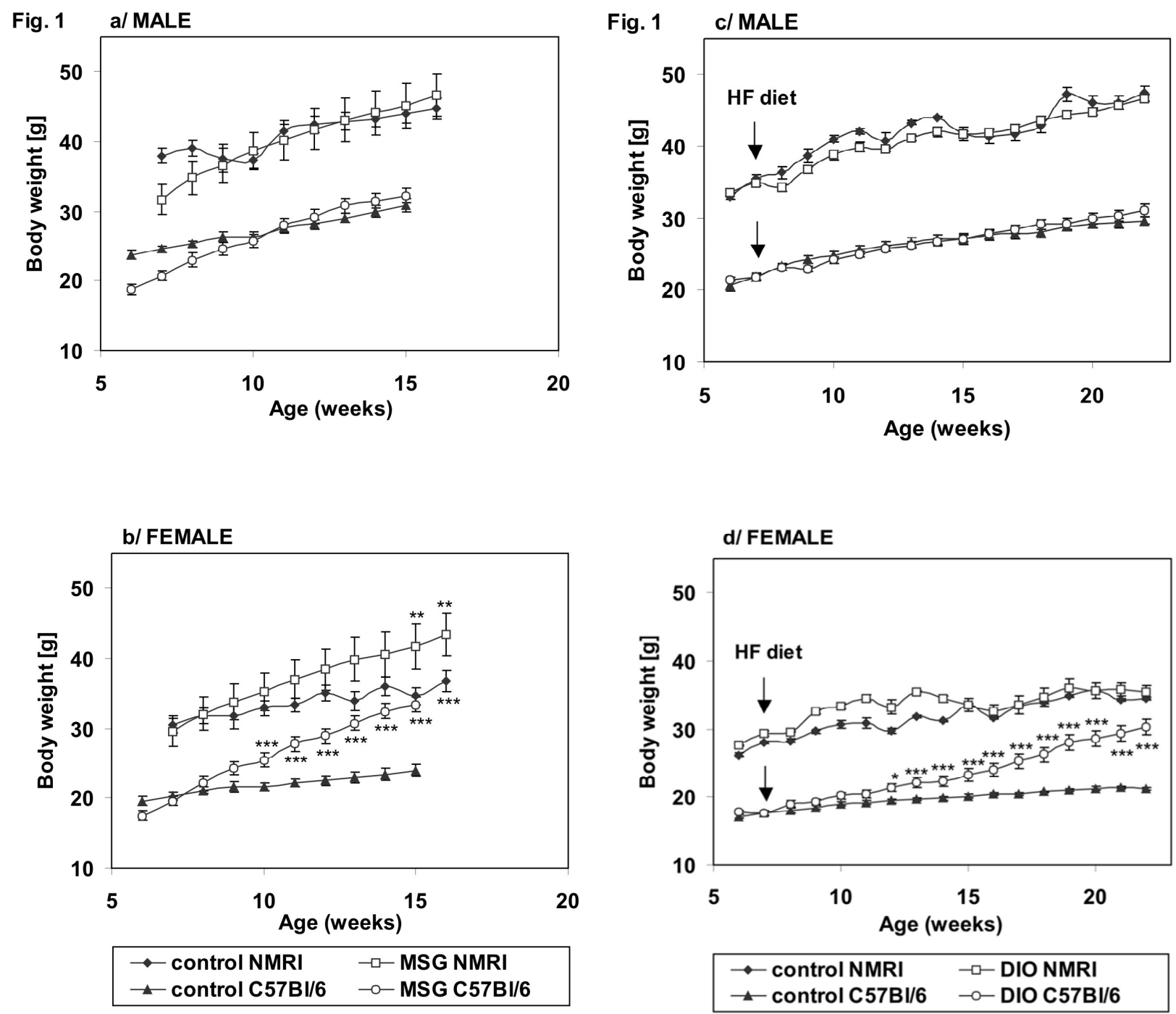

Fig. 1. Increase in body weight of control, MSG-treated and DIO NMRI and C57BL/6 mice: a/ MSG male, b/ MSG female, c/ DIO male, d/ DIO female ( $n=20-25$ per group). Significance is $* P<0.05$, $* * P<0.01$ and $* * * P<0.001$ vs. controls for female mice.

Statistics

Data are presented as means \pm SEM for the number of animals indicated in the Figures and Tables. They were analyzed by two-way ANOVA (obesity $\mathrm{x}$ gender) followed by Bonferroni post hoc test using Graph-Pad Software (San Diego, CA, USA). $\mathrm{P}<0.05$ was considered statistically significant.

\section{Results}

\section{MSG obesity}

Serial coronal sections of the hypothalami both of inbred NMRI and outbred C57BL/6 mice showed that the MSG treatment caused disappearance of neurons exclusively in ARC and did not affect adjacent hypothalamic nuclei, which was in concordance with our previous study (Maletínská et al. 2006). Naive and "osmolality" controls of the MSG obese mice did not display any histological alterations in their hypothalami (data not shown).

Generally, food consumption of robust NMRI mice was higher than that of subtle C57BL/6 mice which resulted from the fact that NMRI mice had about $50 \%$ higher weight than $\mathrm{C} 57 \mathrm{BL} / 6$ at the beginning of the experiment (Fig. 1a-d). Average daily food intake was insignificantly lower in the MSG-treated males and females of both strains compared with their controls (Table 1). Body weight of male MSG obese NMRI and C57BL/6 mice did not differ from that of their controls (Fig. 1a). On the other hand, a significant increase in body weight was obvious in female MSG mice from 15 weeks of age (NMRI) or 9 weeks of age $(\mathrm{C} 57 \mathrm{BL} / 6)$ (Fig. 1b).

All mice with MSG obesity excessively 
Table 1. Average daily food intake ( $\mathrm{g}$ and/or $\mathrm{kJ}$ ) of control, MSG-treated and DIO male and female NMRI and C57BL/6 mice

\begin{tabular}{|c|c|c|c|c|}
\hline \multirow[t]{2}{*}{ Obesity model } & \multirow[t]{2}{*}{ Strain } & \multirow[t]{2}{*}{ Group } & \multicolumn{2}{|l|}{ Sex } \\
\hline & & & Male & Female \\
\hline \multirow{4}{*}{$M S G$} & $N M R I$ & Control & $7.72 \pm 0.76 \mathrm{~g}$ & $6.49 \pm 0.67 \mathrm{~g}$ \\
\hline & & $M S G$ & $5.80 \pm 0.73 \mathrm{~g}$ & $6.15 \pm 0.48 \mathrm{~g}$ \\
\hline & $C 57 B L / 6$ & Control & $4.07 \pm 0.16 \mathrm{~g}$ & $3.96 \pm 0.29 \mathrm{~g}$ \\
\hline & & $M S G$ & $3.62 \pm 0.23 \mathrm{~g}$ & $3.75 \pm 0.30 \mathrm{~g}$ \\
\hline \multirow{5}{*}{ DIO } & $N M R I$ & Control & $\begin{array}{c}7.00 \pm 0.45 \mathrm{~g} \\
(99.67 \pm 6.74 \mathrm{~kJ})\end{array}$ & $\begin{array}{c}5.82 \pm 0.14 \mathrm{~g} \\
(82.94 \pm 2.82 \mathrm{~kJ})\end{array}$ \\
\hline & & $D I O$ & $\begin{array}{c}7.34 \pm 0.54 \mathrm{~g} \\
(163.01 \pm 8.61 \mathrm{~kJ}) *\end{array}$ & $\begin{array}{c}4.53 \pm 0.16 \mathrm{~g} \\
(100.68 \pm 4.39 \mathrm{~kJ})\end{array}$ \\
\hline & & & & \\
\hline & $C 57 B L / 6$ & Control & $\begin{array}{c}4.07 \pm 0.23 \mathrm{~g} \\
(57.92 \pm 1.62 \mathrm{~kJ})\end{array}$ & $\begin{array}{c}3.48 \pm 0.14 \mathrm{~g} \\
(49.62 \pm 1.29 \mathrm{~kJ})\end{array}$ \\
\hline & & $D I O$ & $\begin{array}{c}3.55 \pm 0.27 \mathrm{~g} \\
(78.82 \pm 2.82 \mathrm{~kJ}) *\end{array}$ & $\begin{array}{c}3.14 \pm 0.23 \mathrm{~g} \\
(69.69 \pm 2.96 \mathrm{~kJ}) *\end{array}$ \\
\hline
\end{tabular}

All values are expressed as mean \pm SEM ( $n=20-25$ per group). Significance is $* P<0.05$ (mouse model of obesity vs. respective control).

accumulated subcutaneous, abdominal and gonadal fat and showed dramatically enhanced fat and body weight (Table 2). The liver weight was insignificantly lowered in the MSG obese females and males of both strains, partial steatosis was seen in all MSG animals (Table 2).

All non-fasted mice with MSG obesity had massively increased leptin levels in their blood sera (Fig. 2a,b). NMRI male mice with MSG obesity developed extreme hyperinsulinemia (Fig. 2a); this was in agreement with their HOMA index (Table 3), which was dramatically enhanced in MSG NMRI males compared with their controls ( $241.9 \pm 59$ vs. $8.5 \pm 0.6$ ) (Table 3 ). HOMA index is an indicator of relative insulin resistance and was calculated from glucose and insulin levels after 17-h fasting. Insignificantly enhanced HOMA index was also registered in MSG females of both strains (Fig. 2b, Table 3). However, in fed MSG females of both strains, glucose level did not differ significantly from controls, although insulin level was significantly elevated (Fig. 2b).

\section{DIO obesity}

As shown in Table 1, the amount of food consumed per day by DIO and control C57BL/6 mice did not differ significantly, but logically, energetic intake was higher in mice fed with HF diet compared with controls consuming standard diet, except of NMRI females (Table 1). NMRI mice of both sexes on HF diet (Fig. 1c,d) did not show any significant alterations in their body weight during development of DIO compared with their controls. Female C57BL/6 mice with DIO had significantly increased body weight compared with their controls since 6 weeks on the HF diet, i.e. since 13 weeks of age (Fig. 1d). The increase in body weight of C57BL/6 males was insignificant compared with their controls.

Both male and female C57BL/6 mice with DIO excessively accumulated subcutaneous, abdominal, and gonadal fat (Table 2); after 12 weeks on HF diet the fat to body weight ratio was substantially enhanced (percent of body fat ratio was $3.7 \pm 1.14$ for male controls and $10.76 \pm 2.74$ for DIO males; $2.33 \pm 0.38$ for female controls and $12.04 \pm 4.78$ for DIO females, $\mathrm{P}<0.01$ for both males and females). In DIO C57BL/6 females, liver had significantly pronounced steatosis (Table 2). On the contrary, increase in fat weight was not significant in NMRI DIO mice of both sexes after 16 weeks on HF diet (Table 2).

Leptin and glucose levels but not insulin level were significantly enhanced in C57BL/6 mice of both sexes with DIO (Fig. 2a,b). Significant increase in insulin level was registered only in female C57BL/6 mice but was not accompanied with an increase in HOMA index. Metabolic parameters of NMRI mice with DIO did not show significant differences compared with lean controls, except of glucose level in females (Fig. 2b). 
Table 2. Characterization of control, MSG-treated and DIO NMRI and C57BL/6 mice subjected to $17 \mathrm{~h}$ fasting at 16 weeks (for MSG) or at 23 weeks (for DIO) of age

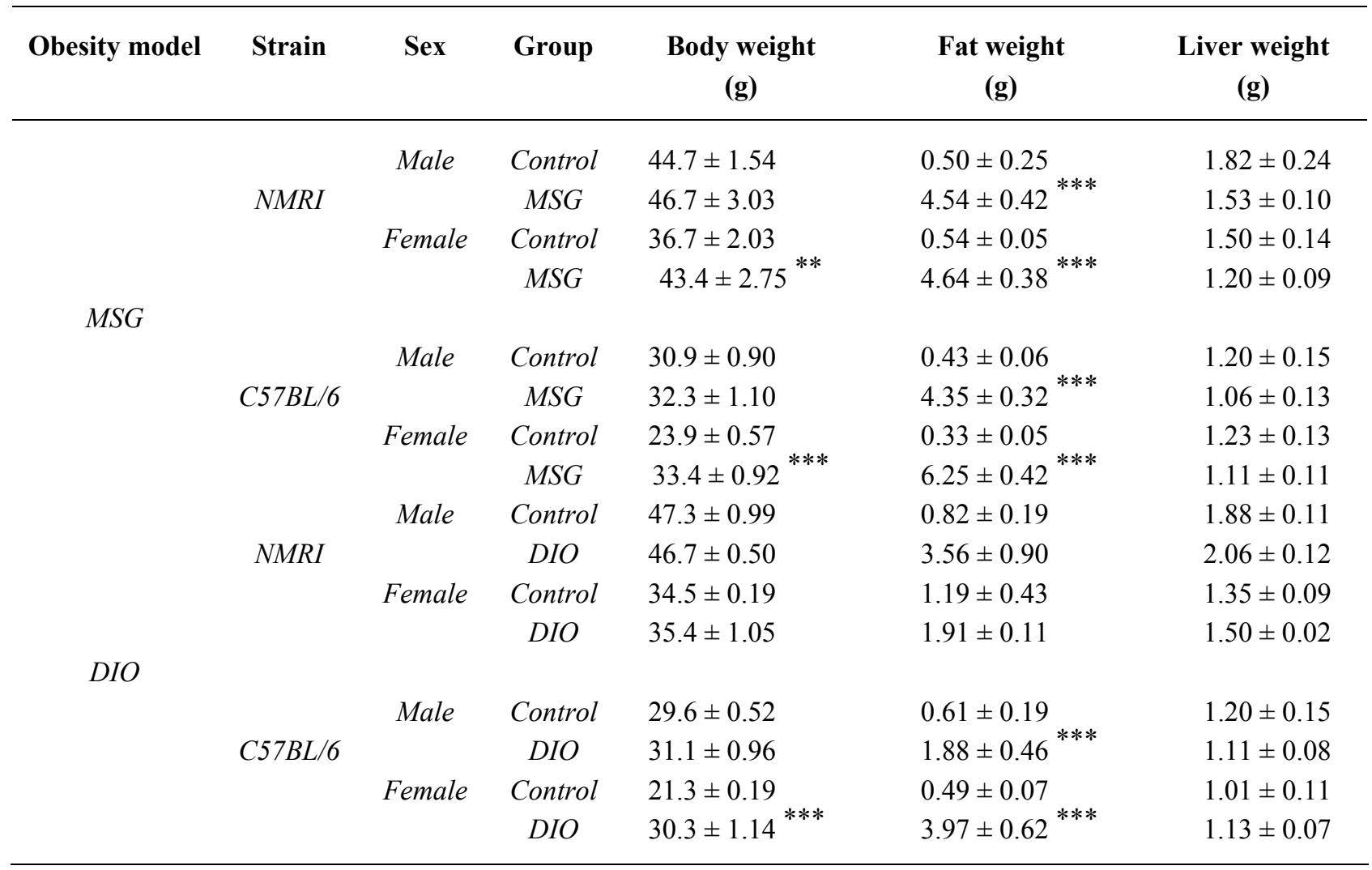

All values are expressed as mean \pm SEM ( $n=20-25$ per group). Significance is $* * P<0.01$ and $* * * P<0.001$ (mouse model of obesity vs. respective control).

\section{Discussion}

\section{MSG obesity}

In mice with MSG-induced obesity, the number of cells was decreased by $75 \%$ in the ARC, but it was unchanged in other hypothalamic areas (Elefteriou et al. 2003). The relationship between MSG-induced damage of the ARC and the metabolic changes that produce obesity at mild hypophagia is poorly understood, one of the basic factors is probably the lack of leptin receptors in ARC (Dawson et al. 1997). In this study, MSG treatment of both NMRI and C57BL/6 males resulted in massive enhancement of adipose tissue despite an insignificantly lower food intake and no significant difference in body weight compared with their respective controls. On the other hand, female mice of both strains significantly increased their body weight after the MSG treatment. At 16 weeks of age, fat to body weight ratio of $\mathrm{C} 57 \mathrm{BL} / 6$ mice was about 10 times (males) to 20 times (females) higher compared to control mice, whereas in NMRI strain, it was about 8 times higher than in controls both in males and females. Our findings are in agreement with previous data on $\mathrm{C} 57 \mathrm{BL} / 6$ mice with MSG obesity (Matsuki et al. 2003, Hollopeter et al. 1998). Although the liver had obvious steatosis, its weight was lowered most probably because of lower production of GHRH resulting in smaller organs similarly as it was described for pituitary and gonads (Tamura et al. 2002).

Markedly elevated leptin levels in both MSG obese $\mathrm{C} 57 \mathrm{BL} / 6$ and NMRI mice pointed to a severe hyperleptinemia, which was more pronounced in females whose leptin level is usually higher than in males. In fed NMRI mice, levels of insulin and glucose were enhanced, but those after $17 \mathrm{~h}$ of fasting persisted only in NMRI MSG male mice. It is evident from HOMA index, which was 28 times higher for MSG males compared with lean controls, that the male NMRI mice were more prone to insulin resistance than the female ones and $\mathrm{C} 57 \mathrm{BL} / 6$ mice of both sexes. C57BL/6 mice with MSG obesity of both sexes did not show significantly elevated levels of glucose and insulin, unlike Matsuki et al. (2003) who found elevated insulin level in C57BL/6J male mice. 

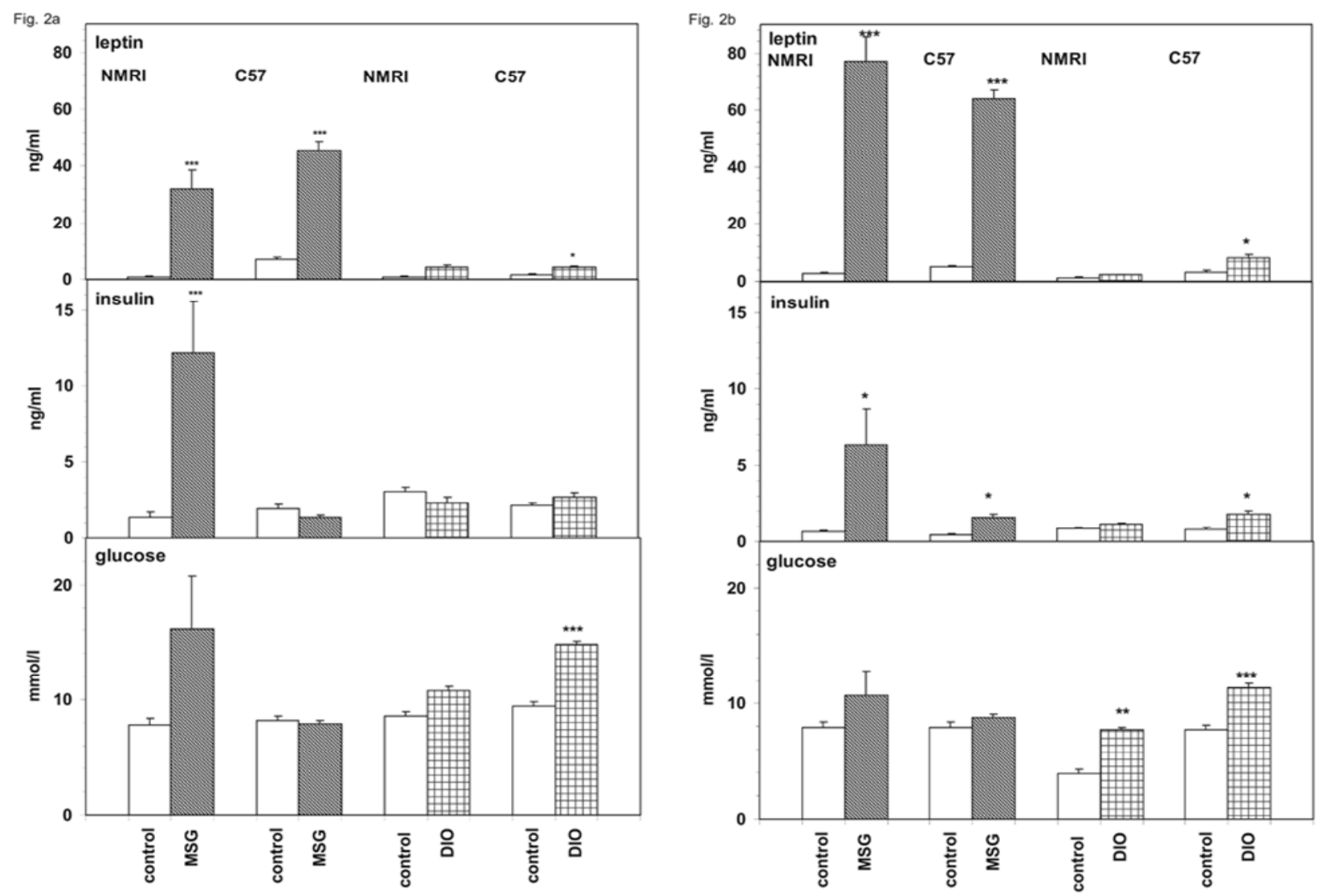

Fig. 2. Serum leptin, insulin and glucose levels in fed a/ male and b/ female NMRI and C57BL/6 mice with MSG obesity and DIO and their controls ( $\mathrm{n}=10-15$ per group). $* \mathrm{P}<0.05, * * \mathrm{P}<0.01$ and $* * * \mathrm{P}<0.001$ (mouse model of obesity vs. respective controls).

Table 3. Metabolic parameters of control and MSG-treated NMRI and C57BL/6 mice mice subjected to $17 \mathrm{~h}$ fasting at 16 weeks of age

\begin{tabular}{|c|c|c|c|c|c|}
\hline Strain & Sex & Group & Glucose (mmol/l) & Insulin (ng/ml) & HOMА \\
\hline \multirow{4}{*}{$N M R I$} & Male & Control & $5.55 \pm 1.88$ & $0.20 \pm 0.04$ & $8.5 \pm 0.6$ \\
\hline & & $M S G$ & $9.50 \pm 2.56^{*}$ & $3.31 \pm 3.00^{* *}$ & $241.9 \pm 59.0 * * *$ \\
\hline & Female & Control & $5.65 \pm 0.86$ & $0.33 \pm 0.10$ & $9.2 \pm 0.1$ \\
\hline & & $M S G$ & $5.75 \pm 0.94$ & $0.52 \pm 0.10$ & $14.7 \pm 1.3$ \\
\hline \multirow{4}{*}{$C 57 B L / 6$} & Male & Control & $3.48 \pm 0.54$ & $0.38 \pm 0.09$ & $10.2 \pm 0.4$ \\
\hline & & $M S G$ & $3.19 \pm 0.55$ & $0.65 \pm 0.31$ & $15.9 \pm 1.3$ \\
\hline & Female & Control & $4.59 \pm 0.28$ & $0.26 \pm 0.02$ & $14.3 \pm 0.7$ \\
\hline & & $M S G$ & $2.98 \pm 0.75$ & $0.64 \pm 0.23$ & $23.0 \pm 0.7$ \\
\hline
\end{tabular}

All values are expressed as mean \pm SEM $(n=10-15$ per group). Significance is $* \mathrm{P}<0.05, * * \mathrm{P}<0.01$ and $* * * \mathrm{P}<0.001$ (mouse model of obesity vs. respective control).

C57BL/6 mouse strain is widely used for development of diet-induced obesity (Lee et al. 2005, Thupari et al. 2004, for review see Buettner et al. 2007). Lin et al. (2000) described that DIO C57BL/6 male mice showed increased body weight, adiposity and leptin and developed leptin resistance after 19 weeks on HF diet.
However, they were later divided into obesity-resistant (without changes in body weight after HF diet) and obesity-susceptible groups (Huang et al. 2003). In this study, C57BL/6 male mice with DIO obesity did not show a significant increase in their body weight compared with their lean controls (about $1.5 \mathrm{~g}$, Table 2) 
although their increase in fat weight was significant (increase about $1.3 \mathrm{~g}$, Table 2) and corresponded to the increase in body weight. It means that the lean weight remained unchanged. Park et al. (2005) also found no change in lean mass at an increased fat mass in C57BL/6 mice after 20 weeks on HF diet. However, their study lacked the data between 5 and 20 weeks on HF diet. Unlike males, female C57BL/6 DIO mice in our study substantially increased body weight already after 5 weeks on HF diet (in agreement with Huang et al. (2003)) and accumulated seven times more adipose tissue. Both C57BL/6 females and males significantly increased leptin and glucose level compared with their lean controls, but only females had also significantly elevated insulin level. HOMA index in all fasted DIO mice did not show any significant difference from that of fasted controls.

HF diet up to 6 months did not significantly alter body weight in female NMRI mice (Huang et al. 2003). In our study, NMRI DIO mice of both sexes did not show any changes in anatomical and metabolic parameters, except of elevated glucose level in males.

\section{Conclusions}

The early-onset MSG obesity resulted in substantially increased fat to body weight ratio in both strains and both sexes. MSG obese males and females of both strains had dramatically increased leptin levels resulting from attenuated leptin signaling in ARC and being a good model of ARC-located leptin resistance.
Only outbred NMRI MSG male mice developed complex diabetes-obesity syndrome similar to the $(d b / d b)$ genotype mutation (Harris et al., 2001) and thus showed up as a favorable model for studies of insulin resistance.

In C57BL/6 animals but not in NMRI mice, lateonset DIO resulted in substantially increased fat to body weight ratio. Unlike inbred $\mathrm{C} 57 \mathrm{BL} / 6$, outbred NMRI females did not significantly tend to fat accumulation and development of changes in the metabolic parameters after being on high-fat diet. DIO obesity resulted in significant hyperleptinemia and hyperglycemia in C57BL/6 of both sexes but not in NMRI mice; insulin level was significantly elevated only in C57BL/6 females. Female C57BL/6 DIO mice showed the most significant fat accumulation besides significantly elevated leptin, glucose and insulin levels. We therefore consider them useful for study of obesity, obesity-related metabolic syndrome and leptin resistance based on gender differences.

\section{Conflict of Interest}

There is no conflict of interest.

\section{Acknowledgements}

The study was supported by grants 303/05/0614 of the Grant Agency of the Czech Republic and Z4 0550506 of the Academy of Sciences of the Czech Republic. We are indebted to A. Vytejčková and H. Vysušilová for their excellent technical assistance.

\section{References}

ANDRIKOPOULOS S, MASSA CM, ASTON-MOURNEY K, FUNKAT A, FAM BC, HULL RL, KAHN SE, PROIETTO J: Differential effect of inbred mouse strain (C57BL/6, DBA/2, 129T2) on insulin secretory function in response to a high fat diet. $J$ Endocrinol 187: 45-53, 2005.

BROBERGER C, JOHANSEN J, JOHANSSON C, SCHALLING M, HOKFELT T: The neuropeptide Y/agouti generelated protein (AGRP) brain circuitry in normal, anorectic, and monosodium glutamate-treated mice. Proc Natl Acad Sci USA 95: 15043-15048, 1998.

BUETTNER R, SCHOLMERICH J, BOLHEIMER LC: High-fat diets: Modeling the metabolic disorders of human obesity in rodents. Obesity 15: 798-808, 2007.

BUTLER AA, CONE RD: Knockout models resulting in the development of obesity. Trends Genet 17: S50-S54, 2001.

COLLINS S, MARTIN TL, SURWIT RS, ROBIDOUX J: Genetic vulnerability to diet-induced obesity in the C57BL/6J mouse: physiological and molecular characteristics. Physiol Behav 81: 243-248, 2004.

DAWSON R, PELLEYMOUNTER MA, MILLARD WJ, LIU S, EPPLER B: Attenuation of leptin-mediated effects by monosodium glutamate-induced arcuate nucleus damage. Am J Physiol 273: E202-E206, 1997.

DJAZAYERY A, MILLER DS, STOCK MJ: Energy balances in obese mice. Nutr Metab 23: 357-367, 1979.

ELEFTERIOU F, TAKEDA S, LIU X, ARMSTRONG D, KARSENTY G: Monosodium glutamate-sensitive hypothalamic neurons contribute to the control of bone mass. Endocrinology 144: 3842-3847, 2003. 
HARRIS RBS, MITCHELL TD, YAN X, SIMPSON JS, REDMANN JR SM: Metabolic responses to leptin in obese $\mathrm{db} / \mathrm{db}$ mice are strain dependent. Am J Physiol 281: R115-R132, 2001.

HOLLOPETER G, ERICKSON JC, PALMITER RD: Role of neuropeptide Y in diet-, chemical and genetic-induced obesity of mice. Int J Obes 22: 506-512, 1998.

HUANG X, HAN M, SOUTH T, STORLIEN L: Altered levels of POMC, AgRP and MC4-R mRNA expression in the hypothalamus and other parts of the limbic system of mice prone or resistant to chronic high-energy dietinduced obesity. Brain Res 992: 9-19, 2003.

HUANG X, HANSSON M, LAURILA E, AHREN B, GROOP L: Fat feeding impairs glycogen synthase activity in mice without effects on its gene expression. Metabolism 52: 535-539, 2003.

JEŽOVÁ D, KISS A, TOKAREV D, ŠKULTÉTYOVÁ I: Stress hormone release and propiomelanocortin mRNA levels in neonatal rats treated with monosodium glutamate to induce neurotoxic lesions. Stress Medicine 14: 255-260, 1998.

KOPECKÝ J, HODNÝ Z, ROSSMEISL M, SYROVÝ I, KOZAK LP: Reduction of dietary obesity in aP2-Ucp transgenic mice: physiology and adipose tissue distribution. Am J Physiol 270: E768-E775, 1996.

LANSANG MC, WILLIAMS GH, CARROLL JS: Correlation between the glucose clamp technique and the homeostasis model assessment in hypertension. Am J Hypertens 14: 51-53, 2001.

LEE JH, BULLEN JW, JR, STOYNEVA VL, MANTZOROS CS: Circulating resistin in lean, obese, and insulinresistant mouse models: lack of association with insulinemia and glycemia. Am J Physiol 288: E625-E632, 2005.

LIN S, THOMAS TC, STORLIEN LH, HUANG XF: Development of high fat diet-induced obesity and leptin resistance in C57B1/6J mice. Int J Obes Relat Metab Disord 24: 639-646, 2000.

MALETÍNSKÁ L, SHAMAS TOMA R, PIRNIK Z, KISS A, SLANINOVÁ J, HALUZÍK M, ŽELEZNÁ B: Effect of cholecystokinin on feeding is attenuated in monosodium glutamate obese mice. Regul Pept 136: 58-63, 2006.

MATSUKI T, HORAI R, SUDO K, IWAKURA Y: IL-1 plays an important role in lipid metabolism by regulating insulin levels under physiological conditions. J Exp Med 198: 877-888, 2003.

MORRIS MJ, TORTELLI CF, FILIPPIS A, PROIETTO J: Reduced BAT function as a mechanism for obesity in the hypophagic, neuropeptide Y deficient monosodium glutamate-treated rat. Regul Pept 75-76: 441-447, 1998.

OLNEY JW: Brain lesions, obesity and others disturbances in mice treated with monosodium glutamate. Science 164: 719-721, 1969.

PARK SY, CHO YR, KIM HJ, HIGASHIMORI T, DANTON C, LEE MK, DEY A, ROTHERMEL B, KIM YB, KALINOWSKI A, RUSSEL KS, KIM JK. Unraveling the temporal pattern of diet-induced insulin resistance in individual organs and cardiac dysfunction in C57B1/6 mice. Diabetes 54: 3530-3540, 2005.

TAMURA H, KAMEGAI J, SHIMIZU T, ISHII S, SUGIHARA H, OIKAWA S. Ghrelin stimulates GH but not food intake in arcuate nucleus ablated rats. Endocrinology 143: 3268-3275, 2002.

THUPARI JN, KIM E, MORAN TH, RONNETT GV, KUHAJDA FP: Chronic C75 treatment of diet-induced obese mice increases fat oxidation and reduces food intake to reduce adipose mass. Am J Physiol 287: E97-E104, 2004.

VAN HEEK M, COMPTON DS, FRANCE CF, TEDESCO RP, FAWZI AB, GRAZIANO MP, SYBERTZ EJ, STRADER CD, DAVIS HR JR: Diet-induced obese mice develop peripheral, but not central, resistance to leptin. J Clin Invest 99: 385-390, 1997.

WEST DB, BOOZER CN, MOODY DL and ATKINSON RL: Dietary obesity in nine inbred mouse strains. Am $J$ Physiol 262: R1025-R1032, 1992.

ZHANG Y, SCARPACE PJ: The role of leptin in leptin resistance and obesity. Physiol Behav 88: 249-256, 2006. 